\title{
THE ADSORPTION AND DECOMPOSITION OF CARBON MONOXIDE ON Ni(100) AND THE OXIDATION OF THE SURFACE CARBIDE BY OXYGEN
}

\author{
E.G. KEIM, F. LABOHM, O.L.J. GIJZEMAN, \\ G.A. BOOTSMA * and J.W. GEUS \\ Van 't Hoff Laboratory, University of Utrecht, Padualaan 8, 3508 TB Utrecht, The Netherlands
}

Received 5 May 1981; accepted for publication 30 July 1981

\begin{abstract}
The interaction of carbon monoxide with $\mathrm{Ni}(100)$ has been studied by ellipsometry and Auger electron spectroscopy. Bombardment by electrons of a relatively high energy $(2500 \mathrm{cV})$ leads to the disproportionation of the adsorbed $\mathrm{CO}\left(2 \mathrm{CO}_{\mathrm{au}} \rightarrow \mathrm{C}_{\mathrm{ad}}+\mathrm{CO}_{2 \mathrm{~g}}\right)$. The rate of oxidation of this surface carbide is

$-\mathrm{d} h_{\mathrm{C}} / \mathrm{d} t=k_{0} h_{\mathrm{C}} p_{\mathrm{O}_{2}}^{n} \exp \left(-E_{\mathrm{ac}} / R T\right)$,

where $h_{\mathrm{C}}$ is the carbon $272 \mathrm{eV}$ Auger peak height, $n=0.5$ and the apparent activation energy $E_{\text {act }}=13.3 \mathrm{kcal} / \mathrm{mole}$. This relation is valid at $200-400^{\circ} \mathrm{C}$ and at oxygen pressures of $5 \times 10^{-9}-8$ $\times 10^{-7}$ Torr.
\end{abstract}

\section{Introduction}

The interaction of carbon monoxide with nickel single crystals has been studied by many authors [1-24]. It has been observed that the adsorption of $\mathrm{CO}$ on nickel is completely reversible below temperatures of $180^{\circ} \mathrm{C}$, but that at more elevated temperatures, exposure of monocrystalline $\mathrm{Ni}$ surfaces to $\mathrm{CO}$ results in the buildup of carbon. Below $180^{\circ} \mathrm{C}$ buildup of carbon can also be brought about by the incidence of electrons of sufficiently high energy [22-25]. A number of theoretical analyses have dealt with the interaction of $\mathrm{CO}$ with transition metal surfaces below $280^{\circ} \mathrm{C}$ [27]. Disproportionation of $\mathrm{CO}(2 \mathrm{CO} \rightarrow$ $\mathrm{C}_{\mathrm{ad}}+\mathrm{CO}_{2 \mathrm{~g}}$ ) is thermodynamically favoured, but there is evidence that dissociative adsorption is also possible, with formation of a $\mathrm{Ni}-\mathrm{C}$ and a $\mathrm{Ni}-\mathrm{O}$ bond $(2 \mathrm{Ni}+\mathrm{CO} \rightarrow \mathrm{Ni}-\mathrm{C}+\mathrm{Ni}-\mathrm{O})$ [26]. The surface carbon is carbidic and does not react to graphite upon heating in vacuum, but rather diffuses into the bulk [28]. According to Coad and Rivière [33] nickel carbide is not stable above $400^{\circ} \mathrm{C}$ and most of the evidence suggests that it starts to decompose

* Permanent address: Department of Applied Physics, Twente University of Technology, P.O. Box 217, 7500 AE Enschede. The Netherlands. 
slightly below that temperature. During decomposition free carbon is formed.

The oxidation of the carbidic surface by oxygen $[34,35]$ has been investigated less extensively than the reaction with hydrogen $[2,27-32]$.

In the present paper we report our results on:

(i) the adsorption of $\mathrm{CO}$ on $\mathrm{Ni}(100)$ at room temperature, and the influence of surface carbon on the extent of adsorption;

(ii) the electron beam induced disproportionation of adsorbed $\mathrm{CO}$;

(iii) the reactivity of the surface carbon thus obtained with oxygen at temperatures of $200-500^{\circ} \mathrm{C}$ and oxygen pressures of $5 \times 10^{-9}-8 \times 10^{-7}$ Torr.

Ellipsometry, which does not disturb the adsorbed species, was used to monitor the adsorption and decomposition of $\mathrm{CO}$. Auger electron spectroscopy was utilized to obtain the oxidation reaction rates and to determine the surface composition of the $\mathrm{Ni}$ crystal.

\section{Experimental}

Most of the experiments were carried out in a Riber UNI-5 system described previously [36], with facilities for AES - LEED, simultaneous ellipsometry, mass spectrometry and argon ion bombardment. The base pressure was about $10^{-10}$ Torr. The crystal was the same as the one used in previous experiments [37,38]. Ellipsometry was done at an angle of incidence of $68.2^{\circ}$ and at a wavelength of $6328 \AA$ with either two-zone or off-null irradiance measurements.

The remaining experiments were done in a Varian UHV system with the same facilities and with the same crystal as mentioned above. This system had a base pressure of $5 \times 10^{-11}$ Torr. The Auger spectra were obtained in their usual first derivative form $E \mathrm{~d} N(E) / \mathrm{d} E$ using a cylindrical mirror analyser (Varian 981-2707, resolution better than 0.3\%), with an on-axis clectron gun (Varian 981-2713). This electron gun was adjusted to yield an anode current of $260 \mu \mathrm{A}$ at an energy of $2.0 \mathrm{keV}$ and an electron beam diameter smaller than $0.12 \mathrm{~mm}$ at the sample plane. A modulation frequency of $17 \mathrm{kHz}$ and a modulation voltage of 5 or $10 \mathrm{~V}$ peak to peak were used. The spectrometer had an analysis range for Auger electrons of $0-3000 \mathrm{eV}$. A Varian ion bombardment gun and control unit (model 981-0043 and 981-0046) were used for argon ion sputtering. The entire system was bakable up to $250^{\circ} \mathrm{C}$. The gases used, i.e., argon (purity $99.999 \%$ ), oxygen (99.995\%) and carbon monoxide (99.99\%) were manufactured by L'Air Liquide.

After installation in one of the UHV systems and bake-out the crystal was subjected to the cleaning procedure described by Schouten [39]. 


\section{Results}

\subsection{Adsorption of $\mathrm{CO}$ on $\mathrm{Ni}(100)$ at room temperature}

The change in the ellipsometric parameter $\Delta, \delta \Delta=\bar{\Delta}-\Delta$, where $\bar{\Delta}$ is the value for the clean surface and $\Delta$ is the value for the surface with absorbate, is shown in fig. 1. At $\mathrm{CO}$ pressures from $6 \times 10^{-9}$ to $6 \times 10^{-8}$ Torr the coverage saturates after an exposure of about $6 \mathrm{~L}\left(1 \mathrm{~L}=10^{-6}\right.$ Torr $\mathrm{s}=1.33 \times 10^{-4}$ $\mathrm{Pa} \mathrm{s}$ ). This constant saturation coverage $\left(\delta \Delta_{\max }=0.25 \pm 0.05^{\circ}\right)$ corresponds to about 0.6 of a monolayer [19-22]. The change in $\Delta$ could be described by:

$\delta \Delta=\delta \Delta_{\max }[1-\exp (-k t)]$,

with $k=k_{0} p_{\mathrm{CO}}$ (see fig. 2). The initial sticking coefficient was about unity. The fact that the above relation, valid for Langmuir kinetics, holds allows us to infer with some confidence that $\delta \Delta$ is linearly proportional to the CO coverage with $\theta_{\mathrm{CO}}$ (monolayers) $\simeq 2.4 \delta \Delta$ (deg).

No significant changes in $\psi$ were observed during our experiments.

\subsection{Electron beam induced disproportionation of $\mathrm{CO}$ on $\mathrm{Ni}(100)$}

After evacuation the adsorbed $\mathrm{CO}$ was subjected to bombardment with 2.5 $\mathrm{keV}$ electrons from the AES electron gun. This treatment caused the $\mathrm{CO}$ to disproportionate, leaving a surface with carbon but very little oxygen [22]. Monitoring the oxygen AES peak height showed a steady decrease, while in another run the carbon peak height was observed to remain constant (fig. 3). When we prepared a surface with half a monolayer of carbide by means of the thermal decomposition of ethylene [40] we observed, however, a carbon peak that was about 1.7 times as large as the one measured after electron bombard-

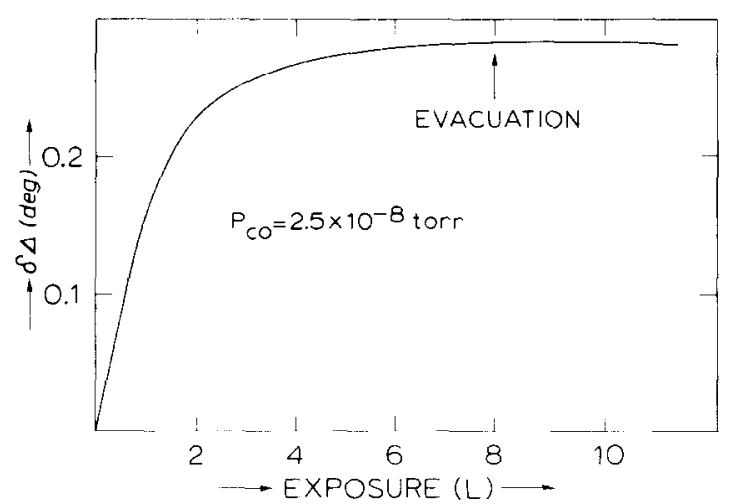

Fig. 1. Adsorption of carbon monoxide on $\mathrm{Ni}(100)$ at room temperature; $\delta \Delta$ as a function of $\mathrm{CO}$ exposure. 


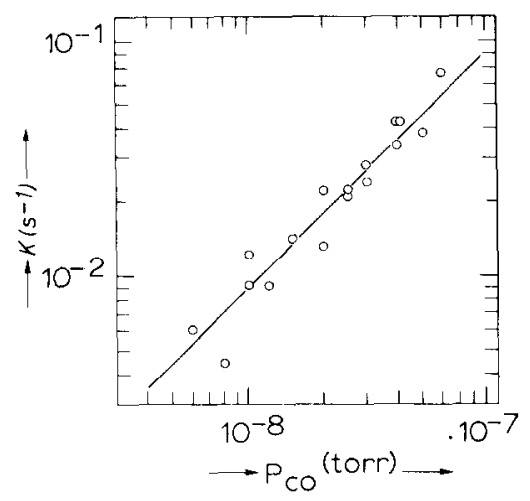

Fig. 2. Rate constant $k$ for $\mathrm{CO}$ adsorption on $\mathrm{Ni}(100)$ at room temperature as a function of $\mathrm{CO}$ pressure.

ment of adsorbed $\mathrm{CO}$. The disproportionation was in most cases accompanied by a simultaneous decrease to zero of $\delta \Delta$ indicating that carbon coverages of up to about one third of a monolayer have no effect on $\Delta$ at the wavelength used $(6328 \AA$ ). In some cases, however, $\delta \Delta$ decreased to a non-zero value, whereas AES indicated that complete disproportionation had occurred. The difference turned out to be caused by an incomplete overlap of the area of the crystal onto which the electron beam was focused, and the area where the $\mathrm{CO}$ coverage was measured, i.e., the area irradiated by the ellipsometer light beam.

Defocusing the electron gun caused $\delta \Delta$ to decrease to zero (fig. 3). The C 272 eV AES lineshape indicated that the carbon deposit thus formed was carbidic.

It was possible to perform a second $\mathrm{CO}$ adsorption/disproportionation cycle on the surface. The amount of $\mathrm{CO}$ adsorbed in this case was roughly half of that taken up by the clean surface (fig. 4). The results described thus far have been obtained with the Riber UHV system.

\subsection{Reaction of the surface carbon with oxygen}

The oxidation reaction was studied in both the Riber and the Varian UHV system. In the Riber system the carbon was deposited as described above. In the Varian system the reactivity of a (carbidic) carbon contamination-typically about a quarter of a monolayer-was studied. In both UHV systems the carbon layer was disordered since the LEED pattern showed no superstructure.

The reaction of oxygen with the surface carbon resulting either from the electron beam induced decomposition of CO (Riber UHV system) or already present (Varian UHV system), was studied at crystal temperatures between 200 and $500^{\circ} \mathrm{C}$, oxygen pressures of $5 \times 10^{-9}$ to $8 \times 10^{-7}$ Torr and initial carbon coverages of 0.05 to 0.3 monolayers.

Interaction with oxygen caused the carbon Auger peak height to decrease, 


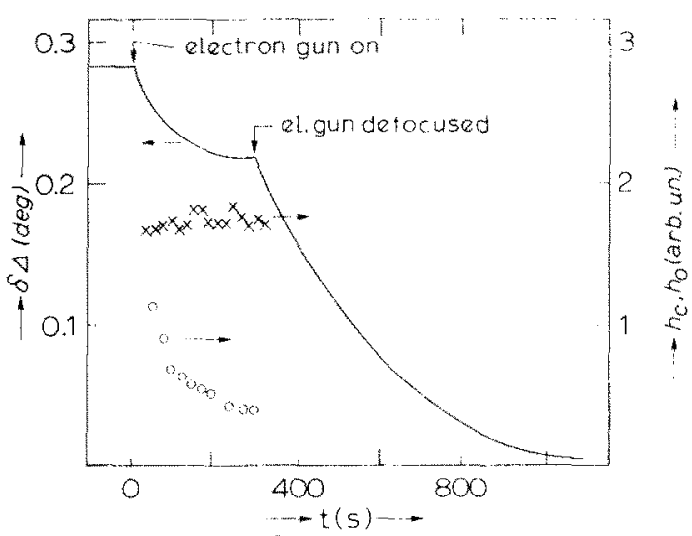

Fig. 3. Electron beam induced disproportionation of $\mathrm{CO}$ on $\mathrm{Ni}(100)$, with the effect of defocusing the electron beam: (- - $\delta \Delta ;(X) h_{\mathrm{C}}(272 \mathrm{eV}) ;(0) h_{\mathrm{O}}(512 \mathrm{eV})$

cf. fig. 5 (lower curve) which shows a semi-logarithmic plot of the carbon peak height versus time. The apparent increase in the reaction rate constant is caused by the fact that the true secondary background of the Auger spectrum varies with energy [41]. The insert in fig. 5 shows that the measured peak height $h=a+b-c$, while the true peak height $h_{C}=a+b$. Therefore $h_{\mathrm{C}}=h+c$, where $c$ is the increase in background signal between the peak and the valley of the Auger line. When this correction is made the upper curve in fig. 5 is obtained. The correction was found to be necessary for both the RFA (Riber) and the CMA (Varian) measurements.

During oxygen exposition the carbon $272 \mathrm{eV}$ pcak was continuously scanned,
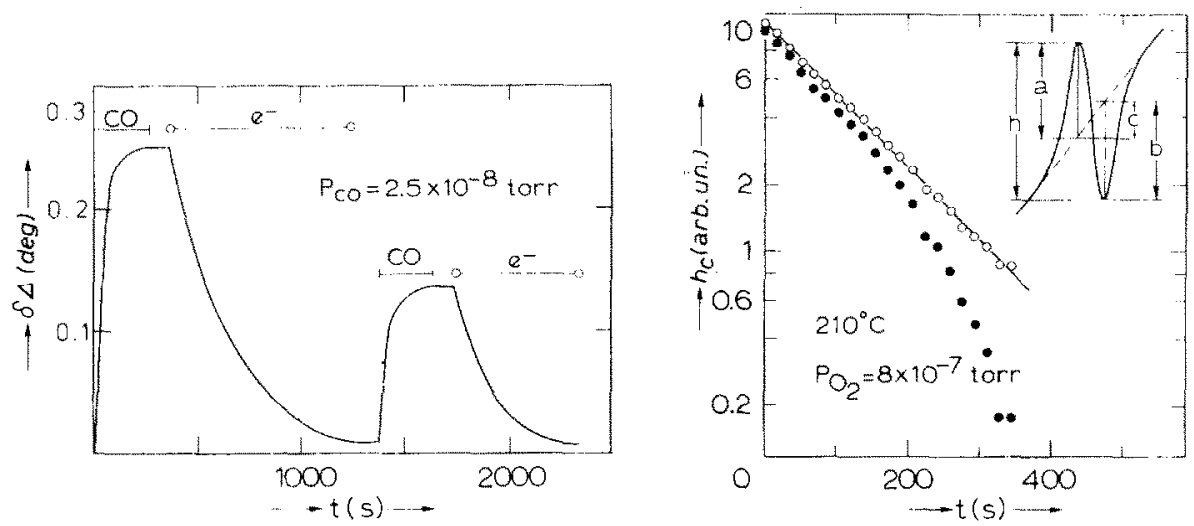

Fig. 4. The effect on $\delta \Delta$ of two $\mathrm{CO}$ adsorption/electron beam induced disproportionation cycles.

Fig. 5. Oxidation of the surface carbide on $\mathrm{Ni}(100):\left(-h_{\mathrm{C}}(272 \mathrm{eV})\right.$ not corrected for background signal; (O) $h_{C}$ corrected for background. Insert: explication of background correction. see text. 


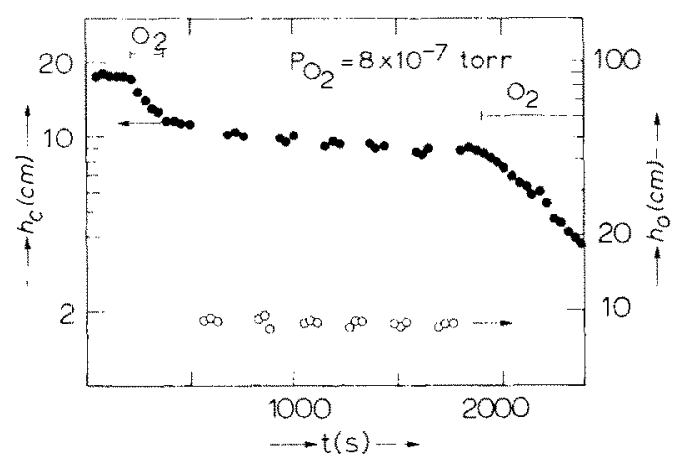

Fig. 6. Oxidation of the surface carbide on $\mathrm{Ni}(100):(9) h_{\mathrm{C}}(272 \mathrm{eV}) ;(0) h_{\mathrm{O}}(512 \mathrm{eV})$.

each scan taking about half a minute. Operation of the AES electron gun did not influence the reaction rate.

Fig. 6 shows that on admission of oxygen the reaction started without an observable induction time. Evacuation caused the reaction to stop abruptly, while on readmission of oxygen the oxidation restarted instantaneously with the same rate constant as before the interruption. The slight decrease in the carbon peak height can be attributed to a small $\mathrm{O}_{2}$ background pressure.

The kinetics of the reaction have been found to obey an empirical rate equation of the form:

$-\mathrm{d} h_{\mathrm{C}} / \mathrm{d} t=\alpha h_{\mathrm{C}}$,

where

$\alpha=\alpha_{0} p_{\mathrm{O}_{2}}^{n} \exp \left(-E_{\mathrm{act}} / R T\right)$.

This rate equation was valid for temperatures of $200-400^{\circ} \mathrm{C}$, oxygen pressures

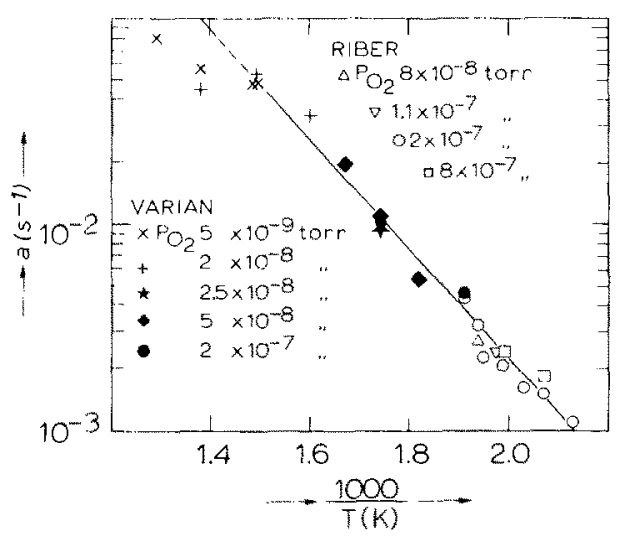

Fig. 7. Arrhenius plot of the oxidation rate; $a=\alpha\left(2 \times 10^{\cdots 7} / p_{\mathrm{O}_{2}}\right)^{1 / 2}$, cf. eq. (2). 


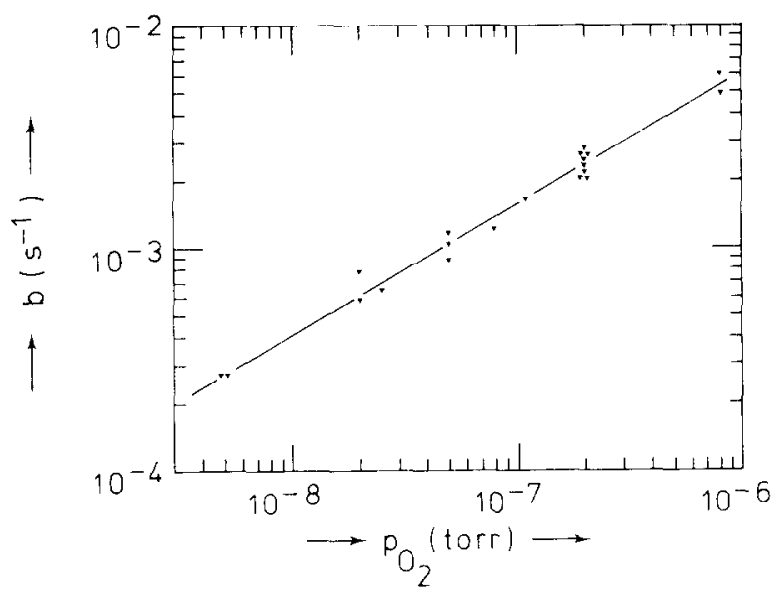

Fig. 8. Pressure dependence of the oxidation rate, scaled to constant temperature $(503 \mathrm{~K})$; $b=\alpha \exp \left[13.3 R^{-1}(1 / 503-1 / T)\right]$. The slope of the line is 0.57 .

of $5 \times 10^{-9}-8 \times 10^{-7}$ Torr and carbon coverages of $0.05-0.3$ monolayers. Using a least squares procedure for simultaneously determining the best values for $n$ and $E_{\text {act }}$ we obtained $n=0.57 \pm 0.1$ and $E_{\text {act }}=13.3 \pm 1.5 \mathrm{kcal} / \mathrm{mole}$. Fig. 7 shows an Arrhenius plot of $\alpha\left(2 \times 10^{-7} / p_{\mathrm{O}_{2}}\right)^{1 / 2}$.

The three data points at $t>400^{\circ} \mathrm{C}$ do not fit, which is not surprising, considering that the incident flux of oxygen atoms from the gas phase is of the same order of magnitude as the number of carbon atoms removed per second
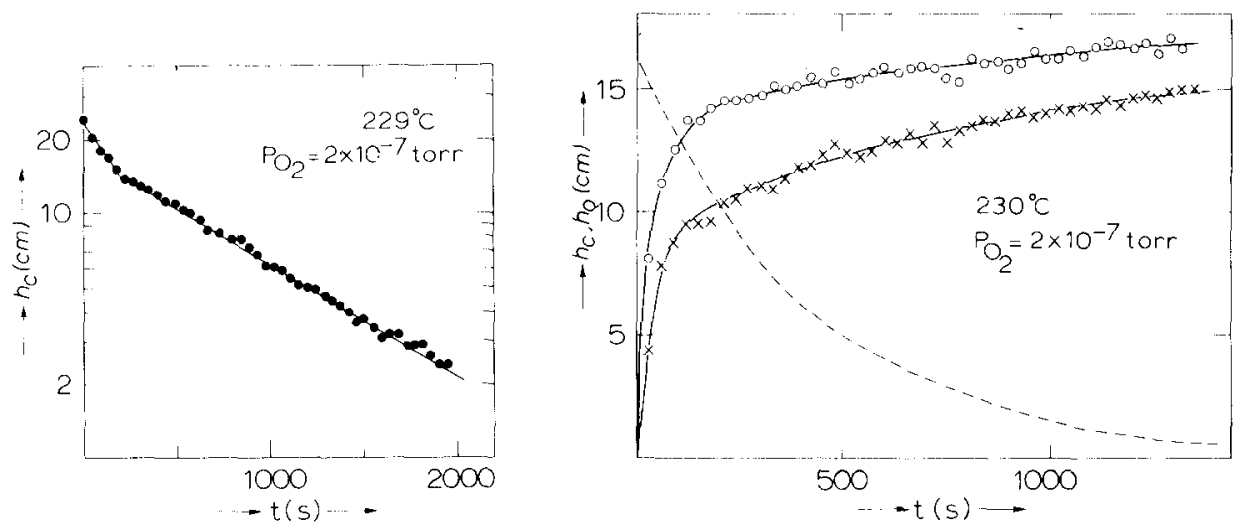

Fig. 9. Oxidation of the surface carbide obtained by means of two $\mathrm{CO}$ adsorption/electron beam induced disproportionation cycles.

Fig. 10. Growth of the oxygen AES peak height on clean and carbide covered Ni(100): (O) $h_{0}$ on clean $\mathrm{Ni}(100) ;(\times) h_{\mathrm{O}}$ on carbide covered $\mathrm{Ni}(100) ;(\ldots \ldots-) h_{\mathrm{C}}$. 
per $\mathrm{cm}^{2}$ at the start of the reaction. These points were therefore not considered in the calculation of $n$ and $E_{\text {act }}$.

Fig. 8 illustrates the pressure dependence of the reaction rate at $t<400^{\circ} \mathrm{C}$. The rate constants $b$ have been calculated for $230^{\circ} \mathrm{C}$ using:

$b=\alpha \exp \left[13.3 R^{-1}(1 / 503-1 / T)\right]$.

When carbon had been deposited by two $\mathrm{CO}$ adsorption/disproportionation cycles the oxidation reaction seemed to proceed in two stages (fig. 9), a fast one and a slower one. The transition occurred when about a third of the initial amount of carbon had been removed. Neither rate constant, however, was in agreement with the one found for carbon deposited by means of a single adsorption/decomposition cycle, and the reproducibility was poor.

After the reaction there was always about half a monolayer of oxygen present on the surface. This coverage was established by comparing the $\mathrm{O} / \mathrm{Ni}$ AES peak height ratio to $h_{\mathrm{O}} / h_{\mathrm{Ni}}$ for a clean surface exposed to $5 \mathrm{~L}$ oxygen at room temperature, and therefore covered with half a monolayer of chemisorbed oxygen [42].

Fig. 10 shows the buildup of oxygen on the surface during the reaction with carbon, the oxidation of a clean Ni surface and the decrease of the amount of carbon, all at the same temperature and oxygen pressure.

\section{Discussion}

Madden and Ertl [23] have provided convincing evidence that electron bombardment of $\mathrm{CO}$ covered $\mathrm{Ni}(110)$ causes the $\mathrm{CO}$ to decompose, leaving a surface with atomically dispersed carbon and oxygen. Concerning $\mathrm{Ni}(100)$, however, the literature is still ambiguous on whether electron bombardment results in the decomposition of adsorbed $\mathrm{CO}$ or whether disproportionation $\left(2 \mathrm{CO}_{\text {ad }} \rightarrow \mathrm{C}_{\mathrm{ad}}+\mathrm{CO}_{2 \mathrm{~g}}\right)$ takes place.

At first sight our results would seem to favour dissociation $\left(\mathrm{CO}_{\mathrm{ad}} \rightarrow \mathrm{C}_{\mathrm{ad}}+\right.$ $\mathrm{O}_{\mathrm{g}}$ ) since the carbon peak height, and therefore presumably the amount of carbon, remains constant during the electron bombardment. When we prepared a surface with 0.5 monolayer of carbidic carbon by means of the thermal decomposition of ethylene, however, we found that this surface gave rise to a carbon AES peak that was 1.7 times as large as the one obtained after the electron bombardment of adsorbed $\mathrm{CO}$. This observation indicates that after the electron bombardment, which started with 0.6 monolayers of $\mathrm{CO}$, we ended up with 0.3 monolayers of surface carbide. This favours disproportionation.

As it turns out there is quite a large difference between the AES lineshape of carbon in $\mathrm{CO}$ and carbon as a surface carbide [43]. By a most unfortunate coincidence this difference in lineshape results (under our experimental conditions) in an AES peak height in the differentiated spectrum that is exactly 
twice as large for carbidic carbon as for carbon in adsorbed $\mathrm{CO}$, assuming equal coverages. Therefore, as the disproportionation proceeds, the decrease of the total number of carbon atoms on the surface is exactly compensated for by the increase in peak height caused by the carbon atoms going from $\mathrm{CO}$ carbon to carbide carbon. We therefore conclude that on electron bombardment of $\mathrm{CO}$ adsorbed on $\mathrm{Ni}(100)$ the $\mathrm{CO}$ disproportionates into surface carbide and $\mathrm{CO}_{2}$ :

$2 \mathrm{CO}_{\mathrm{ad}} \rightarrow \mathrm{C}_{\mathrm{ad}}+\mathrm{CO}_{2 \mathrm{~g}}$.

Fleisch et al. [19] report that $\mathrm{CO}$ exposure to a surface contaminated by about half a monolayer of carbon results in deposition of further carbon, which they ascribed to a disproportionation reaction. We did not observe a different behaviour between $\mathrm{CO}$ adsorption on a clean surface and on a carbon covered surface. On the contaminated surface, however, less $\mathrm{CO}$ could be adsorbed than on the clean surface. Accordingly, sites able to adsorb $\mathrm{CO}$ are partially blocked by adsorbed carbon.

The rate of oxidation of the surface carbide appeared to be first order with respect to carbon coverage. The same result was obtained by Horgan and Dalins [34] for graphitic monolayers on Ni(111) and by Sau and Hudson [35] for carbidic monolayers on $\mathrm{Ni}(110)$. In both these cases, however, the oxidation rate was found to be linear with oxygen pressure, whereas we found a $p_{\mathrm{O}_{2}}^{1 / 2}$ dependence, which indicates a reaction with dissociated (atomic) oxygen although a reaction with a molecular species is not unequivocally excluded [34].

To explain our observations we propose the following reaction mechanism:

$\mathrm{O}_{2 \mathrm{~g}} \rightleftarrows \mathrm{O}_{2 \mathrm{ad}}^{*}$,

$\mathrm{O}_{2 \mathrm{ad}}^{*} \rightleftarrows 2 \mathrm{O}_{\text {aud }}^{*}$,

$\mathrm{C}_{\mathrm{ad}}+\mathrm{O}_{\mathrm{ad}}^{*} \rightarrow \mathrm{CO}_{\mathrm{ad}}$,

$\mathrm{CO}_{\mathrm{ad}} \rightarrow \mathrm{CO}_{\mathrm{g}}$

$\mathrm{O}_{2 \mathrm{ad}}^{*} \rightarrow 2 \mathrm{O}_{\mathrm{ad}}$.

The result of reactions (5) and (6) is a mobile hot [44] precursor $\left(\mathrm{O}_{\mathrm{ad}}^{*}\right)$, the concentration of which is proportional to $p_{\mathrm{O}_{2}}^{1 / 2}$. These $\mathrm{O}_{\mathrm{ad}}^{*}$ are supposedly thermally non-equilibrated atoms that move along the surface with high parallel velocity [44]. They then react with the surface carbon atoms to form $\mathrm{CO}_{\mathrm{ad}}$, which subsequently desorbs (8). Since the reaction rate is proportional to $\left[\mathrm{O}^{*}{ }_{\text {ad }}\right][\mathrm{C}]$ this explains the observed dependence of the reaction rate on $p_{\mathrm{O}_{2}}^{\mathrm{y}} h_{\mathrm{C}}$.

During the oxidation oxygen is deposited on the surface. Fig. 10 shows that the rate of oxygen buildup is somewhat smaller than on the clean surface. It is much faster, however, than the rate of carbon removal. Since the reaction stops instantly on evacuation this surface oxygen must be unreactive towards the surface carbide. We therefore assume a separate adsorption reaction (9) of the 
Ni surface which proceeds more or less independently from the oxidation of the surface carbon and results in an immobile chemisorbed oxygen species $\left(\mathrm{O}_{\mathrm{ad}}\right)$. This oxygen chemisorption reaction, eqs. (5) and (9), is thought to involve a molecular precursor $\left(\mathrm{O}_{2 \mathrm{ad}}^{*}\right)$ since the adsorption rate is known to be linear with respect to $\mathrm{p}_{\mathrm{O}_{2}}[42]$.

\section{Acknowledgement}

We would like to thank Dr. H. Wagner for his valuable comments regarding the absolute carbon coverage.

\section{References}

[1] R.L. Park and H.E. Farnsworth, J. Appl. Phys. 35 (1964) 2220.

[2] M. Onchi and H.E. Farnsworth, Surface Sci. 11 (1968) 203.

[3] T. Edmonds and R.C. Pitkethly, Surface Sci. 17 (1969) 450.

[4] K. Klier, A.C. Zettlemoyer and H. Leidheiser, J. Chem. Phys. 52 (1970) 589.

[5] J.E. Demuth and T.N. Rhodin, Surface Sci. 45 (1974) 249.

[6] J.T. Grant, M.P. Hooker and T.H. Haas, Surface Sci. 46 (1974) 672.

[7] C.R. Helms and R.J. Madix, Surface Sci. 52 (1975) 677.

[8] J.G. McCarthy and R.J. Madix, Surface Sci. 54 (1976) 121.

[9] K. Klier, A.C. Zettlemoyer and H. Leidheiser, J. Chem. Phys. 67 (1977) 11.

[10] K. Horn, A.M. Bradshaw and K. Jacobi, Surface Sci. 72 (1978) 719.

[11] W. Erley and H. Wagner, J. Catalysis 53 (1978) 287.

[12] H. Hopster and C.R. Brundle, J. Vacuum Sci. Technol. 16 (1979) 548.

[13] J.C. Bertolini and B. Imelik, Surface Sci. 80 (1979) 586.

[14] W. Englert, W. Heiland and E. Taglauer, Surface Sci. 83 (1979) 243.

[15] K. Akimoto, Y. Sakisaka, M. Nishijima and M. Onchi, Surface sci. 88 (1979) 109.

[16] G.W. Rubloff, Surface Sci. 89 (1979) 1.

[17] P.S. Bagus and K. Hermann, Surface Sci. 89 (1979) 588.

[18] S.Y. Tong, A. Maldonade, C.H. Li and M.A. Van Hove, Surface Sci. 94 (1980) 65

[19] T. Fleisch, G.L. Ott, W.N. Delgass and N. Winograd, Surface Sci. 81 (1979) 1.

[20] R.S. Bordoli, J.C. Vickerman and J. Wolstenholme, Surface Sci. 85 (1979) 244.

[21] P.H. Dawson and W.C. Tam, Surface Sci. 91 (1979) 153.

[22] J.C. Tracy, J. Chem. Phys. 56 (1972) 2736.

[23] H.H. Madden and G. Ertl, Surface Sci. 35 (1973) 211.

[24] J. Verhoeven and J. Los, Surface Sci. 82 (1979) 109.

[25] G.A. Somorjai, Surface Sci. 34 (1973) 156.

[26] P. Wenticek, B.J. Wood and H. Wise, J. Catalysis 43 (1976) 365.

[27] R.R. Ford, Advan. Catalysis 21 (1970) 51.

[28] R.D. Kelley, D.W. Goodman, T.E. Madey and J.T. Yates, Jr., Conf. on Catalyst Deactivation and Poisoning. Berkeley, 1978; J. Catalysis, submitted.

[29] J.A. Rabo, A.P. Rish and M.L. Poutsma, J. Catalysis 53 (1978) 295.

[30] J.C. McCarthy and H. Wise, J. Catalysis 57 (1979) 406.

[31] P. Biloen, J.N. Helle and W.M.H. Sachtler, J. Catalysis 58 (1979) 95.

[32] D.W. Goodman, R.D. Kelley, T.E. Madey and J.T. Yates, Jr., J. Catalysis 63 (1980) 226.

[33] J.P. Coad and J.C. Rivièrc, Surface Sci. 25 (1971) 609.

[34] A.M. Horgan and I. Dalins, J. Vacuum Sci. Technol. 10 (1973) 523. 
[35] R. Sau and J.B. Hudson, Surface Sci. 102 (1981) 239.

[36] F.C. Schouten, E.W. Kaleveld and G.A. Bootsma, Surface Sci. 63 (1977) 460.

[37] F.C. Schouten, O.L.J. Gijzeman and G.A. Bootsma, Surface Sci. 87 (1979) I.

[38] P.K. de Bokx, F. Labohm, O.L.J. Gijzeman, G.A. Bootsma and J.W. Geus, Appl. Surface Sci. 5 (1980) 321.

[39] F.C. Schouten, Thesis, University of Utrecht (1979).

[40] J.H. Onuferko, D.P. Woodruff and B.W. Holland, Surface Sci. 87 (1979) 357.

[41] E.N. Sickafus, J. Vacuum Sci. Technol. 11 (1974) 299.

[42] P.H. Holloway and J.B. Hudson, Surface Sci. 43 (1974) 123.

[43] M.P. Hooker and J.T. Grant, Surface Sci. 55 (1976) 741.

[44] J. Harris and B. Kasemo, Surface Sci. 105 (1980) L281. 